\title{
USING REASONS FOR NON-COMPLIANCE TO ASSESS PROJECT PERFORMANCE IN THE LAST PLANNER SYSTEM®
}

\author{
Camilo Lagos ${ }^{1}$, Luis Fernando Alarcón ${ }^{2}$, Fabio Basoalto ${ }^{3}$, and Óscar del Río ${ }^{4}$
}

\begin{abstract}
The Last Planner System ${ }^{\circledR}$ (LPS) follows a systematic process of planning and control, in which compliance to short-term commitments is followed weekly and Reasons for Non-Compliance (RNC) are traced for each commitment not accomplished. While most project managers pay close attention to the evolution of the Plan Percent Complete (PPC) indicator to assess project performance, many projects make little or no use of historical data regarding RNCs. The aim of this research is to use quantitative RNC measurements to detect if projects with successful schedule accomplishment present significant differences in their number of RNC, their composition and impact. We gathered weekly information from 23 complete Chilean industrial construction projects and used the Schedule Performance Index (SPI) and Schedule Deviation (SD) at completion to categorize projects into two success groups. We compared LPS compliance indicators between the two groups, such as the Plan Percent Complete (PPC), and RNC metrics, such as their Relative Importance Index (RII), the percentage of internal RNC and the percentage of RNC caused by the main contractor. We found that RNC metrics present significant differences between the groups and can help project managers to establish actions for continuous improvement.
\end{abstract}

\section{KEYWORDS}

Lean Construction, Last Planner System ${ }^{\circledR}$, continuous improvement, Reasons for NonCompliance.

\section{INTRODUCTION}

\section{AIM AND SCOPE OF THE RESEARCH}

Most project control metrics are based on the amount of work performed, efficiency and efficacy in achieving goals, whilst few metrics are focused on the quantity, composition and impact of recurrent problems, which can help detect and prevent project deviations (Hamzeh, El Samad, and Emdanat 2019; Samad, Hamzeh, and Emdanat 2017). Our aim

1 PhD Student, School of Engineering, Pontificia Universidad Católica de Chile, Santiago, Chile, colagos@ing.puc.cl, orcid.org/0000-0002-0648-0039

2 Professor of Civil Engineering, Pontificia Universidad Católica de Chile, Santiago, Chile, lalarcon@ing.puc.cl, orcid.org/0000-0002-9277-2272

3 Student, School of Engineering, Pontificia Universidad Católica de Chile, Santiago, Chile, fjbasoalto@uc.cl, orcid.org/0000-0003-4711-6302

4 Student, School of Engineering, Pontificia Universidad Católica de Chile, Santiago, Chile, ofdelrio@uc.cl,orcid.org/0000-0002-0509-7070 
is to understand how the measurement of Reasons for Non-Compliances (RNCs) in the Last Planner System (LPS) can complement the assessment of schedule performance.

We addressed the research question: What statistically significant differences can be detected in the composition and impact of RNCs between industrial construction projects with different schedule accomplishment? And three objectives were set: (1) create standardized metrics to categorize projects based on schedule performance, (2) identify differences in common LPS indicators between successful and less-than successful projects and (3) propose quantitative RNC metrics that allow to significantly differentiate successful and less-than successful projects. We focused on industrial construction projects since most of previous research has addressed mainly high-rise and residential building projects (Alarcón et al. 2008; Daniel, Pasquire, and Dickens 2015).

We used a sample of 23 complete industrial construction projects that used the software IMPERA to sustain LPS, and addressed differences in their LPS indicators and RNCs. IMPERA was created by the Pontifical Catholic University of Chile to sustain a complete, standardized, implementation of LPS and allow the systematical collection of project performance data (Alarcón and Calderón 2003). It has been implemented in more than 480 projects and its database has been used in several research projects (Alarcón, Salvatierra, and Letelier 2014; Lagos, Herrera, and Alarcón 2019).

\section{TRADITIONAL APPROACH TO PROJECT MANAGEMENT}

Projects face uncertainty and variability (Howell, Laufer, and Ballard 1993; Koskela 1999). Hence, managers face limitations when planning their execution in advance due to complexity and internal or external factors that can cause variation, such as economics, supply, labour or productivity (Howell, Laufer, and Ballard 1993). The traditional approach to manage uncertainty has been to place time buffers between activities, that allow a determined variation to occur without affecting the schedule (Ballard 2000). Variability increases over the consecutive execution of subsequent activities and time buffers prevent its detection until significant deviations in project schedule are observed (Gonzalez, Alarcón, and Mundaca 2008; Zegarra and Alarcón 2017).

\section{TRADITIONAL PROJECT CONTROL SYSTEMS}

Systematic control based on Key Performance Indicators (KPI) is critical to prevent deviations and adjust plans (Chan and Chan 2004; Sarhan and Fox 2012). Traditional control uses result-oriented KPI to address cost, time and scope. Most traditional metrics assess the schedule and budget based on the Earned Value Method (EVM) (Abdel Azeem, Hosny, and Ibrahim 2014; Lipke et al. 2009; Sarhan and Fox 2012). EVM uses detailed schedules with resource allocation to construct planned and actual progress curves, were earned schedule and budget are measured (Abdel Azeem, Hosny, and Ibrahim 2014). Table 1 shows the KPI used to track schedule accomplishment in EVM. These metrics aggregate the value earned by all the activities executed to construct an overall progress index, compare it to the expected progress and determine rates of accomplishment and deviation and, thus, can hide variability when compensating the deviations from different activities (Alarcón, Salvatierra, and Letelier 2014; Sarhan and Fox 2012).

The use of result-oriented KPI has been criticized as lagging control, since they measure results rather than processes (Toor and Ogunlana 2010). Also, relying on buffers prevents the detection of early signs of variability, because they can be expended and project goals can still be achieved, but the margin for future variation reduces. Processoriented indicators can aid to control the variability in process execution, but, their 
complementary use with process-oriented KPI is far less common practice than the strict dependency on result-oriented KPI (Sarhan and Fox 2012; Toor and Ogunlana 2010).

Table 1: Earned Value Method Indicators (Lipke et al., 2009; Azeem et al., 2014)

\begin{tabular}{ccc}
\hline Indicator & Formula & Description \\
\hline $\begin{array}{c}\text { Schedule Performance } \\
\text { Index (SPI) }\end{array}$ & EV / PV & $\begin{array}{c}\text { Earned Value over Planned Value, measured by } \\
\text { cost or workdays }\end{array}$ \\
Schedule Variance (SV) & EV - PV & $\begin{array}{c}\text { Difference between Earned Value and Planned } \\
\text { Value, measured by cost or workdays } \\
\text { Difference, in days, between the Earned } \\
\text { Schedule and actual date of control }\end{array}$ \\
Schedule Deviation (SD) & ES - AT & $\begin{array}{c}\text { (ES - AT) / ES } \\
\text { Difference between Earned Schedule and Actual } \\
\text { Date, over Earned Schedule, in percent }\end{array}$ \\
\hline
\end{tabular}

The Lean Construction community has proposed to integrate process and result oriented systems of control through the Last Planner System (Ballard 2000). In LPS, project managers pay great attention to the accomplishment of short-term schedules and register the recurrence of common problems affecting the short-term plans (Howell and Koskela 2000), thus allowing to systematically assess variability and its causes.

\section{The Last Planner System ${ }^{\circledR}$}

LPS manages projects in three scopes (Ballard 2000; Ballard and Tommelein 2016). First, Long term plans define the basic schedule milestones, which are planned from end to finish, using a method called Phase Scheduling (PS). PS allows managers to create flexible plans without hiding float and then explicitly allocate activity buffers when float is needed between milestones. Second, the Lookahead Plan (LP) represents the mid-term, comprised of activities in a 3 to 12 weeks horizon. Every week, new activities are added to the LP to maintain the horizon and the team searches for mid-term constraints. Constraints are managed to prepare work and constraint-free tasks that compose the Workable Backlog (WB) are pulled to the short-term period. The WB is used at the third planning scope to develop short-term schedules, usually comprised of one to two weeks, were tasks are analysed with the workforce to develop execution commitments.

LPS exercises control at the three scopes. Traditional methods such as EVM are used to monitor schedule, budget and scope at the long-term (Novinsky et al. 2018; PonzTienda et al. 2015). At mid-term, control is focused on work preparation and constraint removal. Tasks Made-Ready (TMR) measures the WB over the number of tasks planned for the upcoming week in the LP to assess work preparation (Hamzeh and Aridi 2013), while Percent Constraints Removed (PCR) measures the number of constraints removed over the number of constraints planned for the upcoming week (Lagos, Herrera, and Alarcón 2019). At the short-term, Percent Plan Complete (PPC) measures the number of accomplishments over the number of tasks committed and a Reason for Non-Compliance (RNC), which is a standardized type of problem linked to a specific cause and root source, is registered for each unaccomplished commitment (Ballard and Tommelein 2016).

\section{NEED FOR NEW METRICS IN THE LAST PLANNER SYSTEM}

LPS has proven to be highly beneficial to project management, increasing productivity, reducing variability and improving performance (Alarcón et al. 2008; Ballard and 
Tommelein 2016; Daniel, Pasquire, and Dickens 2015; Liu, Ballard, and Ibbs 2011). Although, researchers have found that most projects present partial implementations, focusing mostly on short-term planning (Daniel, Pasquire, and Dickens 2015; Dave, Hämäläinen, and Koskela 2015). We reviewed the cientific research carried out by the Lean Construction community between 2009 and 2019 regarding LPS and the contributions made to improve their understanding and deployment, in order to identify the needs and opportunities to improve LPS implementation. We found that most projects use compliance indicators such as the PPC only to make short-term adjustments, while few used the historical information of PPC, PCR or RNC to take long-term actions for continuous improvement (Dave, Hämäläinen, and Koskela 2015). The lack of focus on mid and long term is found to be due, partly, to the lack of understanding of how LPS information can help assess long term objectives and partly due to the need of quantitative research to establish success criteria for LPS metrics aligned with long term objectives (Daniel, Pasquire, and Dickens 2015; Hamzeh, El Samad, and Emdanat 2019).

Several metrics that show the relationship between work preparation, short-term compliance and project performance have been proposed to alingn the short and long term scopes (Hamzeh, El Samad, and Emdanat 2019; Kim 2019; Liu, Ballard, and Ibbs 2011; Samad, Hamzeh, and Emdanat 2017). Many of these have been incorporated into Information Technology (IT) support systems for LPS such as IMPERA and vPlanner, although quantitative assessments of RNCs have yet to be included (Emdanat, Linnik, and Christian 2016; Lagos, Herrera, and Alarcón 2019). Previous work shows that most projects register RNCs weekly, but the majority do not use historical RNC information to establish corrective actions and, it appears, that the use of IT support has not improved this matter yet because projects lack ways to systematically align RNC metrics to shortterm indicators such as PPC and long term objectives like schedule and budget (Lagos, Alarcón, and Salvatierra 2016; Lagos, Herrera, and Alarcón 2019). Altough, the increasing adoption of IT support presents the opportunity to automatically quantify the impact of RNC and link it to short and long term compliance metrics such as the PCR, PPC and SPI, to establish success criteria (Dave, Hämäläinen, and Koskela 2015; Emdanat, Linnik, and Christian 2016; Lagos, Herrera, and Alarcón 2019).

\section{RESEARCH METHODOLOGY}

\section{SAMPLE SELECTION}

We found 23 industrial construction projects, from 5 Chilean companies, that used IMPERA to register weekly information since less than $10 \%$ progress and until completion. They registered compliance indicators for progress (SPI), schedule accomplishment (SD), commitment compliance (PPC), constraint removal (PCR) and detailed information regarding the type, origin, impact and description for each RNC. They had an average planned duration of 33 weeks and an average real duration of 36 weeks. The sample represented a total of 773 weeks and we obtained detailed information from 654 weeks. Each project registered an average of 344 constraints, ranging from 68 to 1272 , and an average of $175 \mathrm{RNC}$, ranging from 43 to 583 , which means that, in average, they registered $7 \mathrm{RNC}$ and 11 constraints per week.

We constructed accumulated indicators for each project using the averages from the total number of weeks in which they used IMPERA. These were the average PPC and PCR, total number of RNC, total number of constraints, and the average number of constraints and RNC per week, normalized per 100 project tasks. We also obtained two 
result indicators: The SPI measured at the end of the planned duration and the SD measured at project completion. In addition, we constructed standardized progress indicators by dividing the project planned duration into ten progress intervals. Each $10 \%$ planned progress interval was represented by the average PPC of that interval, the accumulated PPC average until the end of the interval and the number of RNC.

RNC composition was assessed by creating standardized categories. We categorized the source as "internal" if it originated within the management scope of the project or "external" if it was caused by third parties or uncontrollable events. We also categorized each RNC by the party that originated the problem; these could be the "Main contractor", the "Client" or "Third Parties". We used the detailed description of each RNC to establish their source and party. Table 2 shows the categories that we assessed. Finally, we determined RNC impact by dividing the percent progress achieved in each task over the progress committed for each task at each week.

Table 2: RNC Categories established for source, party and type

\begin{tabular}{|c|c|}
\hline Source & Party \\
\hline $\begin{array}{l}\text { Internal: Causes that should be } \\
\text { controllable by the project, like } \\
\text { coordinating supplies and resource } \\
\text { allocation. }\end{array}$ & $\begin{array}{l}\text { Main contractor: Includes RNC such as planning } \\
\text { errors, labour productivity, work field coordination, } \\
\text { quality issues during execution, internal administrative } \\
\text { procedures, etc. }\end{array}$ \\
\hline $\begin{array}{l}\text { External: Causes that are } \\
\text { uncontrollable like climate issues } \\
\text { and accidents, or controlled by third } \\
\text { parties like delays in supply and } \\
\text { changes in regulatory limitations. }\end{array}$ & $\begin{array}{l}\text { Client: Includes design changes and delays, mandatory } \\
\text { work detention requirements, delivery of work field and } \\
\text { permits, etc. } \\
\text { Third parties: Includes RNC caused by suppliers, } \\
\text { subcontractors or other contractors in the work field, } \\
\text { inspectors and externals. }\end{array}$ \\
\hline
\end{tabular}

\section{Performance CATEgorization}

We classified project outcome using schedule measurements, namely their final SPI and SD. We used a two dimensional K-means algorithm to create clusters with similar results regarding schedule accomplishment (Jain 2010), using their SPI and SD. The algorithm created four randomly located centroids and assigned each project to its closest centroid, creating four clusters. Then, it moved each original centroid to the center point of each cluster and repeated the allocation process, until no significant changes were observed between the clusters composition. Each group obtained was composed projects with a similar result. The first cluster represented highly successful projects and the fourth group represented the projects furthest from success, while the separation between the two center clusters represented the classification rule obtained to segregate successful and less-than successful projects. We obtained 11 projects that failed to meet schedule and 12 successful projects that performed according to their planned schedule or better.

\section{ANALYSIS OF DIFFERENCES BETWEEN GROUP INDICATORS}

We analysed the existence of differences between the accumulated indicators from the two groups using statistical test for mean differences. First, we used the Shapiro Wilk to determine which samples followed a normal distribution. The null hypothesis "the sample follows a normal distribution" was tested using a 95\% confidence interval and it could be rejected when the resulting p-value was higher than 0.05 (Hernández, Fernández, and Baptista 2006). We applied the t-test to establish differences in the means between the two groups when we could not reject the null hypothesis in any of the groups and used 
the Mann Whitney $U$ test for the remaining samples. We used the null hypothesis "There is no significant difference between the groups" in both tests using a 95\% confidence level, meaning that it could be rejected when the $p$-value was equal or lower than 0.05 (Hernández, Fernández, and Baptista 2006). We used this test for each of the accumulated indicators and also for the accumulated and partial PPC of each interval.

\section{ANALYSIS OF DIFFERENCES IN RNC COMPOSITION}

We used the total number of RNC by source in each project to construct a Percent Internal RNC (PIR) indicator, which allowed to determine which RNC source was most relevant in each project. PIR was calculated as the number of RNC catalogued as internal over the entire number of RNC for each project. We constructed a similar indicator for party, the "Percent of RNC caused by the main contractor", that measures the number of RNC caused by the main contractor over the entire number of RNC for each project, thus, allowing to assess whether the majority of the RNC originated under the contractor management or were caused by other parties. In addition, we constructed an indicator to compare the relevance of a determined category of RNC. This indicator was based on the Relative Importance Index (RII) which has been used previously to compare different factors and causes of project delay (Aziz 2013; Gebrehiwet and Luo 2017).

RII measures the weighted frequency of a response, usually in a qualitative Likert scale, over the frequent of the responses. This means that, for example, if a three-point Likert scale is used for weight types of RNC and the majority of the responders assigned 2 points to a determined type, while a few of them assigned 3 points, then the RII will be slightly higher than 2 . Since we counted with quantitative data por frequency and average impact, we modified the RII, creating the Quantitative Relative Importance Index (QRII), which uses impact instead of weight responses, multiplies it by the frequency for a determined category and then divides it for the average result of all the categories. Table 3 shows an example of QRII calculation. We used the QRII to determine a ranking of RNC and then compared the QRII between the successful and less-than successful groups.

Table 3: Example of QRII calculation method

\begin{tabular}{ccccc}
\hline RNC by party & Frequency & Impact & $\begin{array}{c}\text { Weighted } \\
\text { relevance (WR) }\end{array}$ & QRII \\
\hline Description & $\begin{array}{c}\text { Number of } \\
\text { observations }\end{array}$ & $\begin{array}{c}\text { Average deviation in } \\
\text { planned progress }\end{array}$ & $\begin{array}{c}\text { Frequency * } \\
\text { Impact }\end{array}$ & $\begin{array}{c}\text { WR }_{\mathrm{i}} \text { / average } \\
\text { WR }_{\mathrm{n}}\end{array}$ \\
\hline Main contractor & 2170 & $53 \%$ & 1158 & 1.46 \\
Client & 1312 & $60 \%$ & 783 & 0.99 \\
Third parties & 835 & $53 \%$ & 439 & 0.55 \\
\hline Average & 1439 & $55 \%$ & 793 & 1 \\
\hline
\end{tabular}

\section{CORRELATION ANALYSIS BETWEEN RNC COMPOSITION AND RESULT}

After establishing quantitative metrics for RNC composition, we tested correlations between the percentage of internal RNC, the percentage of RNC caused by the main contractor, the SPI and SV, over the entire sample. We used the Pearson correlation coefficient $r$ and considered the existence of a moderate correlation when the absolute value of $r$ was equal or higher than 0.4 , strong when it was equal or greater than 0.6 and highly-strong if it was equal or greater than 0.8 (Hernández, Fernández, and Baptista 2006). 


\section{RESULTS}

\section{PERFORMANCE CATEGORIZATION}

The clustering results showed that the successful project groups had a SD equal or lower than $5 \%$ and a SPI equal or higher than $96 \%$. If a project did not fulfil any of the criteria, it was categorized as less-than successful in terms of schedule accomplishment. Figure 1 shows the project segregation results.

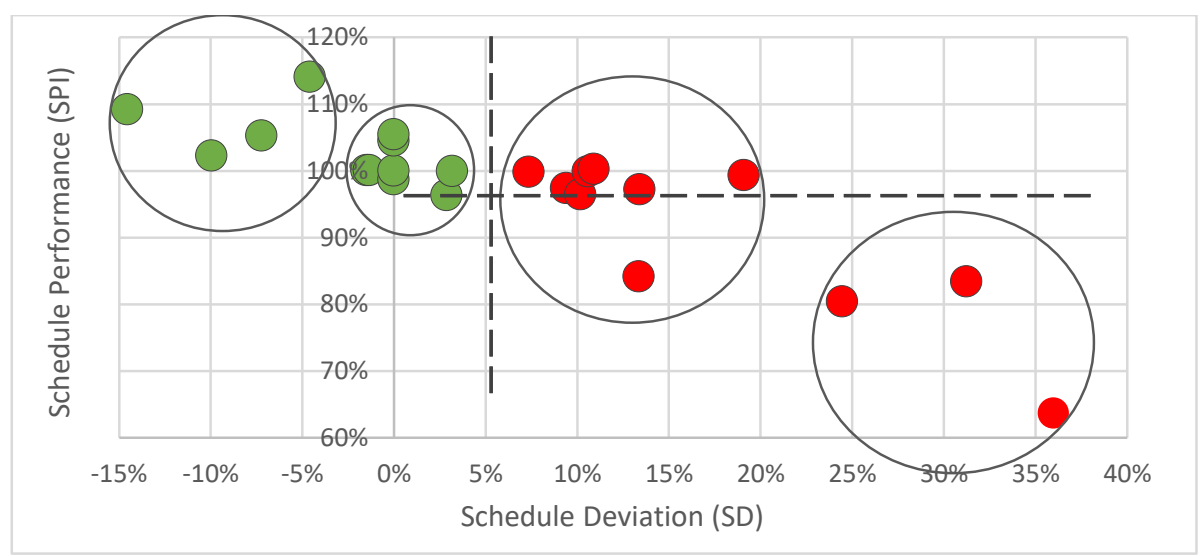

Figure 1: Project categorization based on schedule accomplishment clustering

\section{DIFFERENCES IN THE ACCUMULATED INDICATORS}

We were not able to find significant differences between the groups regarding the PPC average, PCR average, RNC average and RNC per week. But, we found a significant difference in the total number of constraints and, when we normalized the average number of constraints per week by the total number of tasks in each project, we found that projects that meet their planned schedule manage twice as many constraints per task per week than projects with significant schedule deviations. Table 4 summarizes our results.

Table 4: Differences in Accumulated LPS Indicators

\begin{tabular}{|c|c|c|c|}
\hline Group Means & Success & Failure & Difference ratio \\
\hline Number of projects & 12 projects & 11 projects & \\
\hline Final SPI & $103.0 \%$ & $91.1 \%$ & $1.13^{* *}$ \\
\hline Final DP & $-2.8 \%$ & $16.9 \%$ & $6.04^{* *}$ \\
\hline PPC Average & $70.5 \%$ & $66.2 \%$ & 1.06 \\
\hline PCR Average & $59.9 \%$ & $67.8 \%$ & 0.88 \\
\hline Total number of RNC & 169 & 194 & 0.87 \\
\hline Total number of constraints & 394 & 242 & $1.63^{*}$ \\
\hline Number of constraints per period & 13,8 & 10,1 & 1.37 \\
\hline Constraints per period by 100 tasks & 8,4 & 4,1 & $2.05^{*}$ \\
\hline-3 & & t to a 9 & \\
\hline
\end{tabular}

We also analyzed differences between the accumulated and partial PPC for the standardized progress intervals. Figure 2 shows that the partial PPC curves cross each 
other while the accumulated PPC curves develop a 3\% to 5\% gap between the groups after the first third of the project, that remains until planned completion. Nevertheless, the difference is too small and the PPC varies between projects within a group. Therefore, none of the differences observed in the accumulated PPC were significant to a $95 \%$ confidence level.
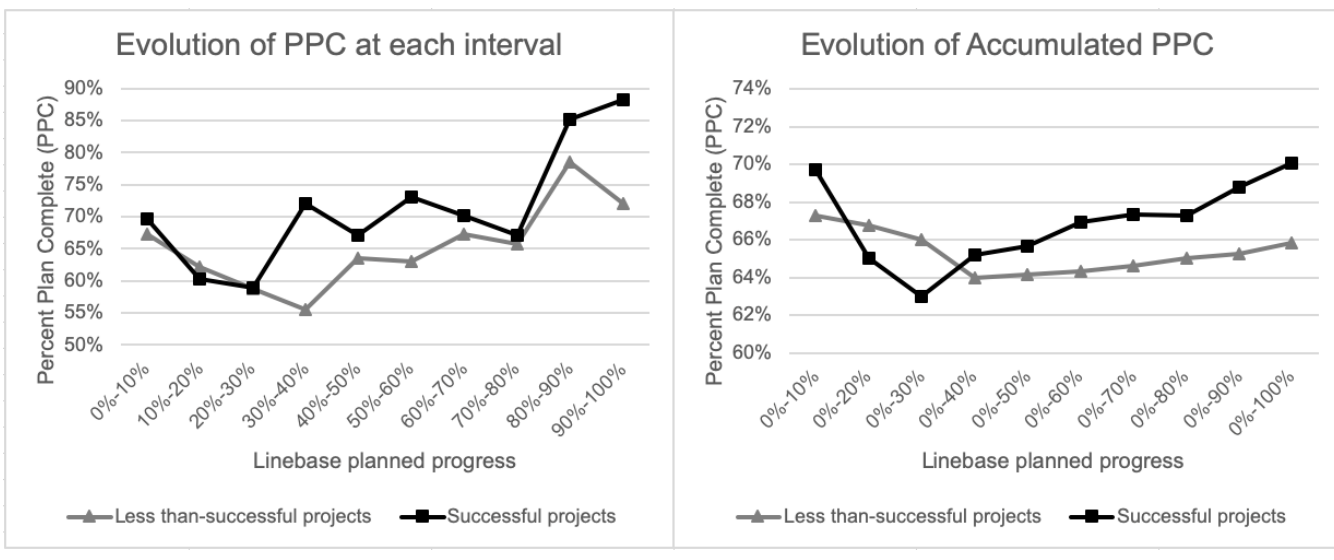

Figure 2: Evolution of the PPC in successful and less-than successful projects

\section{DIFFERENCES IN RNC COMPOSITION}

Table 5 shows the results of the analysis of percent of internal and contractor caused RNC. In addition, we compared the QRII calculated for each source and party, and finally, we calculated ratios between the QRII of internal to external source and the QRII ratio between contractor caused RNC and client caused RNC. We observe that, in successful projects, less than $40 \%$ of their RNC are due to internal causes or generated by the main contractor, while, in less-than successful projects, this causes are responsible for more than $60 \%$ of the total number of RNC.

Table 5: Quantitative indicators for RNC composition

\begin{tabular}{cccc}
\hline Mean RNC indicators by group & Success & Failure & Relative difference \\
\hline Percent of Internal RNC & $39.8 \%$ & $62.5 \%$ & $1.57^{*}$ \\
\hline QRII Internal source & 0.38 & 0.61 & $1.61^{*}$ \\
\hline QRII External source & 0.62 & 0.39 & $0.63^{*}$ \\
\hline QRII ratio of internal to external causes & 0.61 & 1.57 & $2.57^{* *}$ \\
\hline Percent RNC caused by main contractor & $37.8 \%$ & $60.9 \%$ & $1.61^{*}$ \\
\hline QRII Main contractor & 0.54 & 0.92 & $1.70^{*}$ \\
\hline QRII Client & 0.7 & 0.29 & $0.41^{*}$ \\
\hline QRII Third parties & 0.27 & 0.28 & 1.04 \\
\hline Ratio of QRII Main Contractor to Client & 0.77 & 3.2 & $4.16^{* *}$ \\
\hline *Difference is statistically significant to a $95 \%$ level ${ }^{* *}$ Difference is significant to a $99 \%$ level
\end{tabular}

The QRII ratio between internal and externally caused RNCs shows that, in less-than successful projects, internally caused problems are 1.57 times more relevant than external 
problems. When comparing the two groups, it is observed that internally caused RNCs are 2.57 times more relevant in less-than successful projects than in successful projects. In addition, problems caused by the main contractor are 1.61 times more relevant in lessthan successful projects than in successful projects. This difference increases when we analyze the QRII ratio of RNCs caused by the main contractor over RNCs caused by the client. It is observed that in successful projects, the problems caused by the client are more relevant than problems caused by the main contractor, while, in less-than successful projects, the relevance of the problems caused by the main contractor is 3.2 times the relevance of the RNCs caused by the client. This means that the probability of a deviation being caused by the main contractor is 4.16 times more probable in less-than successful projects than in successful projects. Therefore, significant differences in RNC composition and impact are found between successful and less-than successful projects.

\section{CORRELATION BETWEEN RNC METRICS AND SCHEDULE PERFORMANCE}

When analysing the correlation between the SPI, SD, percent of internal RNCs and percent of RNC caused by the main contractor, we found strong correlations between the percent of internal RNC and SD, and between the percent of main contractor caused RNCs and SD. We also found moderate correlations between the percent of internal RNC, percent of main contractor RNC and SPI. Table 6 presents the correlation results and Figure 3 represents the strongest correlation found, between the percent RNC caused by the main contractor and the Schedule Deviation. It must be noted that our results show that as the percent of the project problems that come from internal matters caused by the main contractor increases, the expected schedule performance decreases. This translates to a $5.1 \%$ increase in the schedule deviation for every $10 \%$ increase in the percent of RNC caused by the main contractor.

Table 6: Results of the correlation analyses

\begin{tabular}{ccc}
\hline & \multicolumn{2}{c}{ Pearson $r$ correlation coefficients between indicators } \\
\hline & Percent internal RNC & Percent RNC caused by the main contractor \\
SD & $0.74^{*}$ & $0.77^{*}$ \\
SPI & $0.47^{* *}$ & $0.53^{* *}$ \\
\hline & ${ }^{*} r$ is considered strong if $\geq 0.6$ and ${ }^{* *}$ moderate if between $0.59-0.4$ \\
\hline
\end{tabular}

\section{DISCUSSION}

We found that successful projects have a significantly different RNC composition compared to the less-than successful group. In fact, in projects that meet or surpass schedule objectives, $60.2 \%$ of their RNC belong to external sources and only $37.8 \%$ of their RNC are caused by the main contractor. When analysing the QRII ratio of contractor caused RNC to client caused RNC, we found that, in successful projects, is less probable that a deviation is caused by the main contractor than being caused by the client. In opposite, in less-than successful projects, $62.5 \%$ of the RNCs are due to internal causes and $60.9 \%$ are caused by the main contractor. Also, in less-than successful projects the RNCs caused by the main contractor are 3.2 times more relevant than the problems caused by the client.

The QRII ratio of contractor to client caused RNC shows significant differences between project groups and is found to be a relevant indicator to assess project 
performance. Also, we found that the Schedule Deviation in strongly correlated to the percent of internal and contractor caused RNCs. Hence, if most of the project execution problems are due to internal causes or controllable issues or originated by the main contractor, the expected project outcome will decrease.

Our findings show that assessing the source and party of origin of RNC can allow to complement the continuous control of schedule performance and help to state the relevance of collecting RNC information and using it to act on preventing recurrences, specially when these problems originate from internally controllable sources. Therefore, project managers should pay close attention to the frequency and impact of RNCs caused by different parties and try to minimize internal problems caused by the main contractor. If these problems are significantly more relevant than issues caused by the client or third parties, management should take immediate actions to prevent project deviation. Finally, these results allow the assumption that projects that learn from their RNCs and prevent future recurrences can improve their expected outcome. The validation of this assumption and understanding of the processes underlying it will require further research.

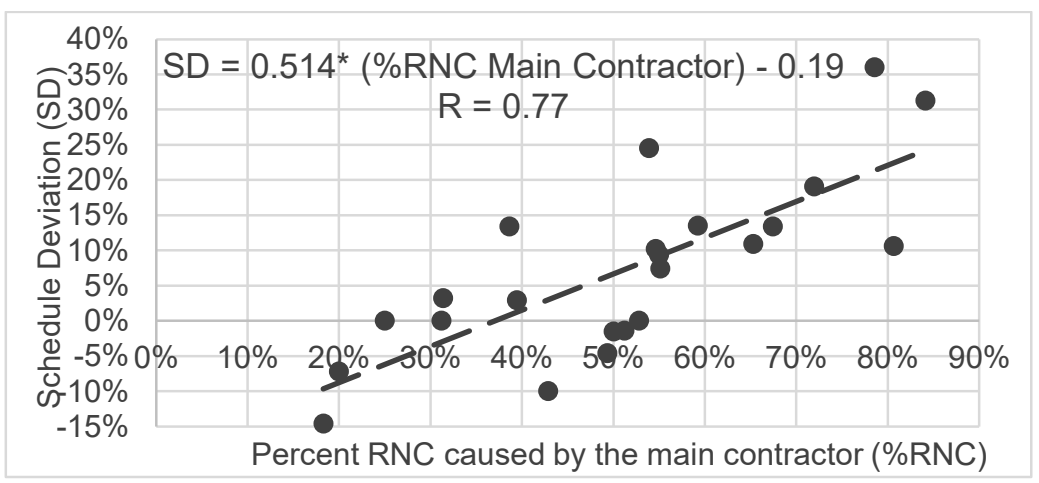

Figure 3: Correlation between SD and RNCs caused by Main Contractor

\section{CONCLUSIONS}

We found that monitoring the composition of project RNC can be complementary to the use of compliance indicators such as the PPC and result indicators such as the SPI and SD. Projects should place special effort in preventing RNC caused by their own management, since it was found that the SD was strongly correlated to the percent of internal and contractor caused RNC. Also, less-than successful projects had roughly $60 \%$ of internal and contractor caused RNC, while successful projects had less than $40 \%$. Our QRII analysis also showed that projects should place special attention to two different planning tasks, first, coordinating workforce and resource allocation to avoid unavailability to enter the work field and, second, planning resource and design procurement in advance, with enough time buffers to avoid that delays in the client or third-party tasks affect the project short-term plans. Finally, we believe that quantitative metrics such as the percent of internal and contractor caused RNC, in addition to the QRII, can be incorporated to IT support systems such as IMPERA to help the use of historical project data in order to decide and implement long-term actions for continuous improvement with the Last Planner System. 


\section{ACKNOWLEDGMENTS}

The authors would like to acknowledge the support provided by the Production Management Centre from the Pontifical Catholic University of Chile (GEPUC), Incolur, Siena Inmobiliaria and GEPRO and also financial support from FONDECYT (1181648) and CONICYT Chile for Camilo Lagos PhD studies.

\section{REFERENCES}

Abdel Azeem, S.A., Hossam E. Hosny, and Ahmed H. Ibrahim. 2014. "Forecasting Project Schedule Performance Using Probabilistic and Deterministic Models." $H B R C$ Journal 10(1): 35-42.

Alarcón, Luis Fernando, and Rodrigo Calderón. 2003. “A Production Planning Support System for Construction Projects." Proc. $11^{\text {th }}$ Ann. Conf. Int. Group for Lean Constr., Virginia, USA.

Alarcón, Luis Fernando, Sven Diethelm, Óscar Rojo, and Rodrigo Calderón. 2008. "Assessing the Impacts of Implementing Lean Construction." Revista Ingenieria de Construccion 23(1): 26-33.

Alarcón, Luis Fernando, José Luis Salvatierra, and Jose Antonio Letelier. 2014. "Using Last Planner Indicators To Identify Early Signs Of Project Performance." Proc. $22^{\text {nd }}$ Ann. Conf. Int. Group for Lean Constr., 547-58.

Aziz, Remon Fayek. 2013. "Ranking of Delay Factors in Construction Projects after Egyptian Revolution." Alexandria Engineering Journal 52(3): 387-406.

Ballard, G. 2000. The Last Planner System of Production Control. PhD Diss., University of Birmingham.

Ballard, Glenn, and Iris Tommelein. 2016. "Current Process Benchmark for the Last Planner System.” Lean Construction Journal 13(1): 57-89.

Chan, Albert P C, and Ada P L Chan. 2004. 11 Benchmarking Key Performance Indicators for Measuring Construction Success.

Daniel, Emmanuel, Christine Pasquire, and Graham Dickens. 2015. "Exploring the Implementation of the Last Planner ${ }^{\circledR}$ System Through Iglc Community: Twenty One Years of Experience." Proc. 23 ${ }^{\text {rd }}$ Ann. Conf. Int. Group for Lean Constr., Perth, Australia (February 2016): 153-62.

Dave, Bhargav, Juho-Pekka Hämäläinen, and Lauri Koskela. 2015. "Exploring the Recurrent Problems in the Last Planner Implementation on Construction Projects." Proceedings of the Indian Lean Construction Conference (ILCC 2015): 1-9.

Emdanat, Samir, Meeli Linnik, and Digby Christian. 2016. "A Framework for Integrating Takt Planning, Last Planner System and Labor Tracking." Proceedings for the 24th Annual Conference of the International Group for Lean Construction. Boston, USA, 20-22 Jul 2016: 53-62.

Gebrehiwet, Tsegay, and Hanbin Luo. 2017. "Analysis of Delay Impact on Construction Project Based on RII and Correlation Coefficient: Empirical Study." In Creative Construction Conference 2017, CCC 2017, 19-22 June 2017, Primosten, Croati,

Gonzalez, Vicente, Luis Fernando Alarcón, and F. Mundaca. 2008. "Investigating the Relationship between Planning Reliability and Project Performance." Production Planning and Control 19(5): 461-74.

Hamzeh, Farook, and Omar Aridi. 2013. "Modeling the Last Planner System Metrics: A Case Study of an Aec Company." proceedings for the 21th Annual Conference of the International Group for Lean Construction. Fortaleza, Brazil: 599-608. 
Hamzeh, Farook, Ghali El Samad, and Samir Emdanat. 2019. "Advanced Metrics for Construction Planning." J. Constr. Engineering and Management 145(11): 1-16.

Hernández, Roberto, Carlos Fernández, and Pilar Baptista. 2006. McGraw-Hill Interametricana Metodología de La Investigación. México D.F.

Howell, Gregory, and Lauri Koskela. 2000. "Reforming Project Management: The Role of Lean Construction." Proc. $8^{\text {th }}$ Ann. Conf. Int. Group for Lean Constr.

Howell, Gregory, Alexander Laufer, and Glenn Ballard. 1993. "Uncertainty and Project Objectives." Project Appraisal 8(1): 37-43.

Jain, Anil K. 2010. "Data Clustering: 50 Years beyond K-Means." Pattern Recognition Letters 31(8): 651-66.

Kim, Yong Woo. 2019. "The Impact of Make-Ready Process on Project Cost Performance in Heavy Civil Construction Projects." Production Planning and Control 30(13): 1064-71.

Koskela, Lauri. 1999. "Management of Production in Construction: A Theoretical View." Proc. $7^{\text {th }}$ Ann. Conf. Int. Group for Lean Constr., 241-52.

Lagos, Camilo, Luis Fernando Alarcón, and José Luis Salvatierra. 2016. "Improving the Use of Information Management for Continuous Improvement With the Last Planner System." Memorias del VII Elagec, Bogotá, Colombia.: 737-45.

Lagos, Camilo, Rodrigo Fernando Herrera, and Luis Fernando Alarcón. 2019. “Assessing the Impacts of an IT LPS Support System on Schedule Accomplishment in Construction Projects." J. Constr. Engineering and Management 145(10): 04019055.

Lipke, W., Zwikael, O., Henderson, K., and Anbari, F. 2009. "Prediction of Project Outcome. The Application of Statistical Methods to Earned Value Management and Earned Schedule Performance Indexes." International Journal of Project Management 27(4): 400-407.

Liu, Min, Glenn Ballard, and William Ibbs. 2011. "Work Flow Variation and Labor Productivity: Case Study." J. Management in Engineering 27(4): 236-42.

Novinsky, M., Nesensohn, C., Ihwas, N., and Haghsheno, S. 2018. "Combined Application of Earned Value Management and Last Planner System in Construction Projects." Proc. $26^{\text {th }}$ Ann. Conf. Int. Group for Lean Constr., 2(0): 775-85.

Ponz-Tienda, José Luís, Eugenio Pellicer, Luis Fernando Alarcón, and Juan RojasQuintero. 2015. "Integrating Task Fragmentation and Earned Value Method Into the Last Planner System Using Spreadsheets." ResearchGate (34): 63-72.

Samad, Ghali El, Farook Hamzeh, and Samir Emdanat. 2017. "Last Planner System The Need for New Metrics." Proc. $25^{\text {th }}$ Ann. Conf. Int. Group for Lean Constr., 63744.

Sarhan, Saad, and Andrew Fox. 2012. "Performance Measurement in the UK Construction Industry and Its Role in Supporting the Application of Lean Construction Concepts." Australasian J. of Construction Economics and Building 13(1): 23-35.

Toor, Shamas Ur Rehman, and Stephen O. Ogunlana. 2010. "Beyond the 'Iron Triangle': Stakeholder Perception of Key Performance Indicators (KPIs) for Large-Scale Public Sector Development Projects." Int. J. of Project Management 28(3): 228-36.

Zegarra, Omar, and Luis Fernando Alarcón. 2017. "Existence of Variability Propagation over the Production Planning \& Control Mechanism of Construction Projects." Production Planning \& Control 7287(April): 1-20. 